\title{
Circumstances and autopsy findings in drownings, Department of Forensic Medicine, Aarhus University, 2006- 2015
}

\author{
Ida Borg Hansen ${ }^{1 *}$, Asser Hedegård Thomsen²
}

'Stud. Med., Aarhus University; Department of Forensic Medicine, Aarhus University, 8200 Aarhus, Denmark ${ }^{2}$ Department of Forensic Medicine, Aarhus University, 8200 Aarhus, Denmark

*E-mail: idaborghansen95@gmail.com

\begin{abstract}
:
The purpose of this study was to examine the demographic circumstances and the autopsy findings regarding drowning deaths autopsied at the Department of Forensic Medicine, University of Aarhus. The study is based on autopsy reports from the Department of Forensic Medicine in Aarhus, 2006- 2015 with drowning as a cause of death. Among the 135 cases of the study, 87 (64.4\%) were accidents versus $33(24.4 \%)$ suicides. The study showed, that the majority of the drowned $73,3 \%$ were males, especially pronounced in the accidents ( $81.6 \%$ were males). In $60.7 \%$ victims, there was a positive blood alcohol analysis, most often in males. Females with positive alcohol analyses did however have the highest mean alcohol blood level (1.65 versus 1.47 per mile). The most frequent place of the submersions was docks $(24.4 \%)$ and the most frequent time of day was in the evening $(18.00-23.59 ; 19.3 \%)$ and at night $(00.00$ $-05.59 ; 20.0 \%)$. The study shows no significant connection between adipocere and type of water $(\mathrm{OR}=1.21,95 \% \mathrm{Cl}(0.49 ; 2.99), \mathrm{p}=0.68)$, bulging lungs and type of water $(\mathrm{OR}=1.18,95 \% \mathrm{Cl}(0.52 ; 2.70), \mathrm{p}=0.69)$, lung weight and type of water $(\mathrm{z}$-test, $\mathrm{p}=0.38)$ and the amount of pleural effusion and water type ( $z$-test, $p=0.16)$. A significant connection between the presence of pleural effusion and type of water cannot discounted ( $\mathrm{OR}=2.37,95 \% \mathrm{Cl}(1.06 ; 2.44), \mathrm{p}=0.02)$.
\end{abstract}

Keywords:

drowning, emphysema, medico legal autopsy, alcohol, pleural effusion, lung weight, submersions

\section{INTRODUCTION}

In Denmark 60-70 individuals die per year from drowning [1,2], of which approximately 30 cases are accidents [2]. The main focus of this study is to review the demographic circumstances regarding drowning victims examined at the Department of Forensic Medicine, University of Aarhus 2006-2015. An identification of such demographics may aid in prevention of drowning accidents in the Danish community. The department covers the area of the police districts of Northern Jutland, Central- and Western Jutland and Southern Jutland, with a population of 2,156,506 inhabitants [3] and an area of $23,222 \mathrm{~km}^{2}[4,5]$. The focus will be on activity at death, age and blood alcohol levels in the drowning accidents, due to the fact, that alcohol related deaths in young - especially men - previously have been described $[6,7]$.

The post mortem diagnosis of drowning can be difficult and the characteristic autopsy findings are ambiguous. Among the most often described autopsy findings, are internal and external froth, petechiae in the conjunctiva and/or the skin around the eyes, bulging and heavy lungs, aqueous gastric content, adipocere and skin macerations (hands and feet) [8-11]. Froth is a result of proteinaceous oedema fluid from the lungs that are mixed with the water of the submersion. The froth can be found as internal or external froth, but is often missing due to the time the body has spent in water. The asphyxiation process of drowning may lead to the formation of the petechiae, whereas the aqueous gastric content may be a result of swallowing water during the drowning

Adipocere and skin maceration are parts of the putrefaction process.
Normal lung weight is approximately $793 \mathrm{~g}$. for women and $953 \mathrm{~g}$. for men [11]. The lungs of drowned are often heavy due to the logging of water, but they can also appear overinflated and bulging due to an over- distension of the lung tissue [11].

This study will attempt to contribute to the identification of the characteristic autopsy findings in drowning deaths. The main focus will be the amount of pleural effusion, lung weight and spleen weight, including potential differences in salt- and fresh water submersions. Additional focus will concern other findings such as aqueous gastric content and fluid in paranasal sinuses.

The registered autopsy findings in this study have been chosen on the basis of given standard examination at autopsies and present literature. Hadley et al. [10] discovered a smaller and more anaemic spleen in submersions than in strangulations. A normal spleen weight is approximately $155 \mathrm{~g}$. for women and $162 \mathrm{~g}$. for men [11]. Yorulmaz et al. [12] discovered larger lungs with a greater amount of pleural effusion in submersions, including a greater amount of pleural effusion in submersions in salt water than in fresh water. This could be important in pursuance of the mechanism of drowning and the putrefaction process of the body in water. Furthermore it may contribute to clarifying the manner of death, if the body has been moved after submersion.

It is emphasized that the amount of time, the body has been submerged is an important factor when it comes to the amount of pleural effusion, as they discovered decreasing lung weight and increasing amount of pleural effusion in the course of time. 
In the analysis of 219 Danish cases of drowning from 1987 to 1989 Kringsholm et al. [9] discovered that the lung weight decreased and that the amount of pleural effusion increased by time of submersion. They also found, that in $53 \%$ of the cases, a blood alcohol concentration of more than $0.1 \%$ was found, and that a majority of males drowned by accident.

By post mortem-CT examination Hyodoh et al. [13] discovered that the amount of pleural effusion increased in the course of time after death.

\section{METHODS}

We collected 136 autopsy reports (figure 1) with drowning as cause of death, from the Department of Forensic Medicine, University of Aarhus in the time period 2006-2015. Of these cases, one was excluded, as the death did not occur in Denmark. Data from each autopsy report has been registered in a standardized codebook, after which it was registered in the application RedCap (AUH CTU Clinical Trial Unit). In the statistical analysis regarding circumstances, all 135 cases were used. In analysis regarding autopsy findings, two cases have been excluded due to age under 15 years and some cases due to missing data on organ weights, time spent in water and water type. Statistical analysis was done on total lung weight $(n=127)$, bulging lungs $(n=124)$, presence of pleural effusion $(n=127)$, and spleen weight ( $n=125)$ ( $n=$ cases), where the remaining cases are missing due to the above. The amount of time the victims spent in water after death has been considered concerning the pleural effusion.

In cases where possible, certain specific autopsy findings have been registered. All data used in this study is from the autopsy reports, which were completed by the forensic pathologist of each case at the time of the autopsy. This includes the estimated time, the body spent in water from the time of death to the finding of this. The given forensic pathologist of each case likewise, in cooperation with the police, determined the circumstances of death at the time of the autopsy. Concerning the location of the drowning, focus has been on the location of incident rather than the location, where the body was found. This is due to the fact that bodies can move away from the location of incident owing to water current.

Manner of death, gender, age etc. have been compared, and missing data is in general included in all analysis. Concerning alcohol analysis two cases have been excluded due to missing alcohol analysis $(n=133)$. Concerning blood alcohol levels, 63 additional cases were excluded due to missing blood alcohol analysis ( $\mathrm{n}=68$ ).

The statistics have been analysed in Microsoft Excel and $R$ ( $R$ Development Core Team).

\section{RESULTS}

In 2006-2015 an average of 13-14 drowned individuals a year were examined at the Department of Forensic Medicine, University of Aarhus (figure 2).

The average age of the victims were 49 years (95\% Confidence Interval $(\mathrm{Cl})=45.92 ; 52.08)$, in an interval of 0-82 years. Most cases were accidents, followed by suicides and undetermined manner of death (table 1 and 2).

Of the 98 males with alcohol analysis, 67 (68.4\%) had a positive alcohol analysis, with an average blood alcohol level of 1.47 per mille $(n=55)$. Of the 35 women with alcohol analysis, 15 (42.9\%) had a positive alcohol analysis, with an average blood alcohol level of 1.65 per mille $(n=11)$. Having a blood alcohol level above 2,0 per mille or higher can cause distinct symptoms of

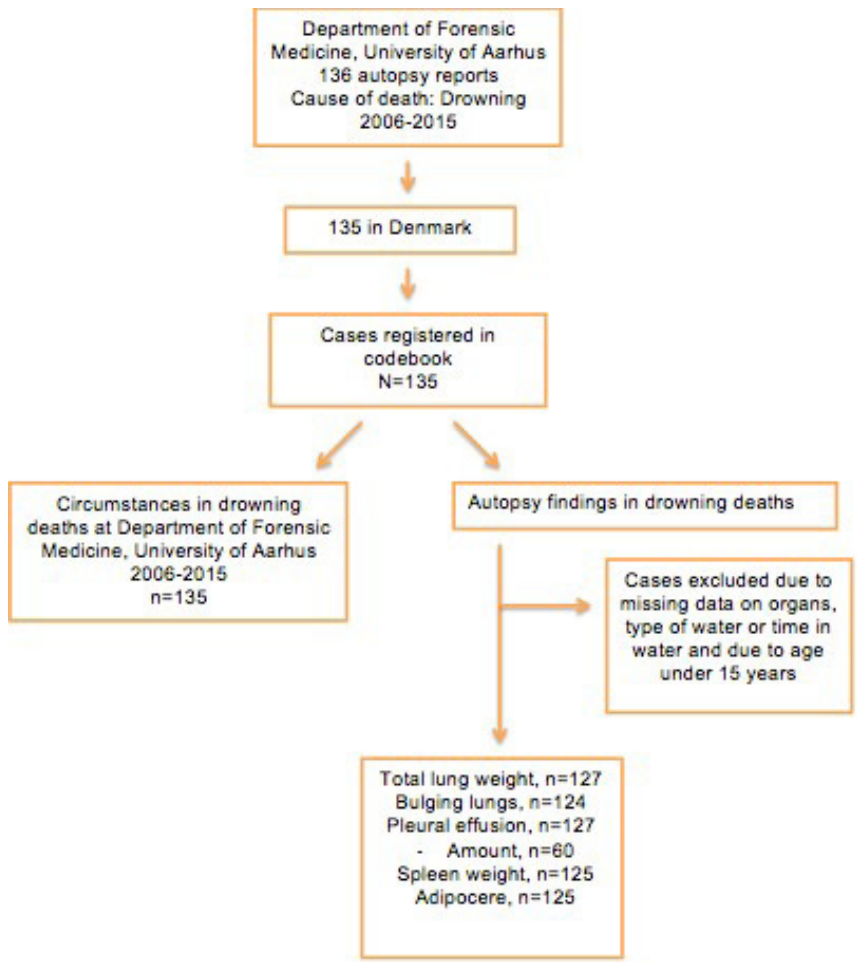

Figure 1. Selection of cases.

Table 1. Mean, and Standard deviation for age in 135 cases.

\begin{tabular}{cc}
\hline Age & \\
\hline $\mathbf{N}$ & 135 \\
Mean & 49 \\
SD & 18 \\
Minimum & 0 \\
Median & 51 \\
Maximum & $\mathbf{8 2}$ \\
\hline
\end{tabular}

Table 2. Absolute and relative distributions of gender, alcohol analysis and manner of death.

\begin{tabular}{ll}
\hline & N (percent) \\
\hline Gender & $99(73.3 \%)$ \\
- Male & $36(26.7 \%)$ \\
- Female & $82(61.7 \%)$ \\
Positive alcohol analysis & \\
Manner of death & $87(64.4 \%)$ \\
- Accident & $33(24.4 \%)$ \\
- Suicide & $15(11.1 \%)$ \\
\hline - Undetermined &
\end{tabular}

poisoning including decreased motor function and loss of consciousness $[14,15]$. Of the 82 cases with a positive alcohol analysis, 19 had a blood alcohol level above 2,0 per mille, making the blood alcohol level a possible influence on the drowning it self.

The average blood alcohol level was highest in the age group of 36-45 years, whereas the lowest average blood alcohol level was found in the age group of 56-65 years (figure 3). 


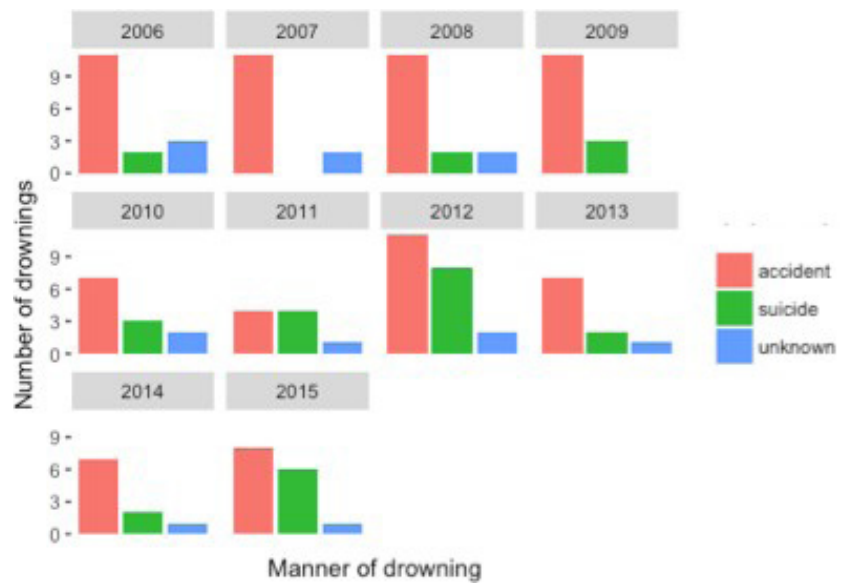

Figure 2. Autopsies of drowning deaths at the Department of Forensic Medicine, Aarhus University, 2006--2015.

Table 3. Absolute and relative distributions of season, time of incident and location of incident of the autopsied. "Other" in location includes e.g. shower stalls and swimming pools.

\begin{tabular}{ll}
\hline Season & N (percent) \\
\hline - Spring & $30(22.2 \%)$ \\
- Summer & $38(28.1 \%)$ \\
- Autumn & $29(21.5 \%)$ \\
- Winter & $37(27.4 \%)$ \\
- Missing & $1(0.70 \%)$ \\
\hline Time of incident & \\
\hline - 06-11.59 & $18(13.3 \%)$ \\
- 12-17.59 & $18(13.3 \%)$ \\
- 18-23.59 & $26(19.3 \%)$ \\
- 00-05.59 & $27(20.0 \%)$ \\
Missing & $46(34.1 \%)$ \\
\hline Location of incident & \\
\hline - Lake/pond & $15(11.1 \%)$ \\
- Open sea & $16(11.9 \%)$ \\
- Beach & $16(11.9 \%)$ \\
- Stream & $19(14.1 \%)$ \\
- Dock & $33(24.4 \%)$ \\
- Bog & $2(1.5 \%)$ \\
- Bath tub & $6(4.4 \%)$ \\
- Fiord & $10(7.4 \%)$ \\
- Other & $6(4.4 \%)$ \\
- Missing & $12(8.9 \%)$ \\
\hline
\end{tabular}

The seasonal distribution of drowning deaths was relatively even with most during summer and winter, and in the evening/night. The most frequent location was docks (table 3 ).

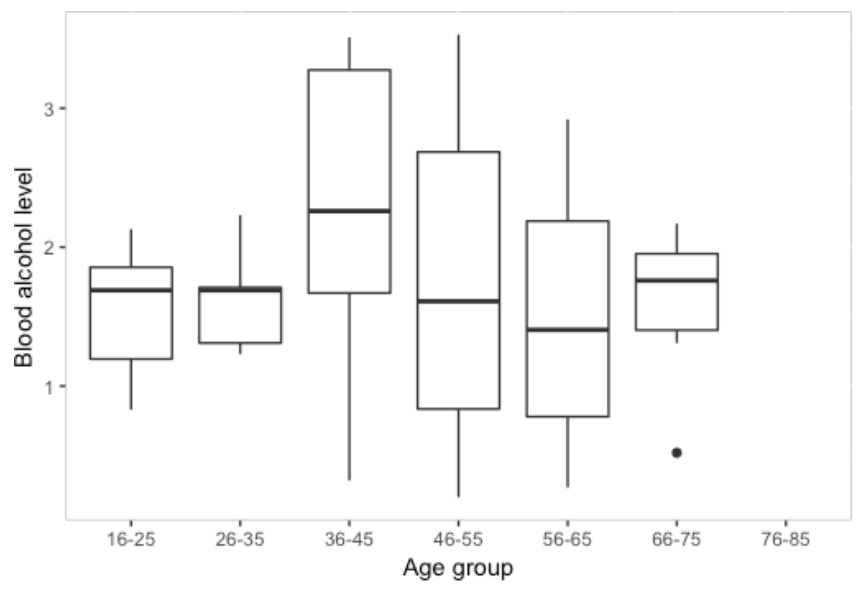

Figure 3. Blood alcohol levels (per mille) in cases of drowning accidents where there were positive blood alcohol analysis, age grouped.

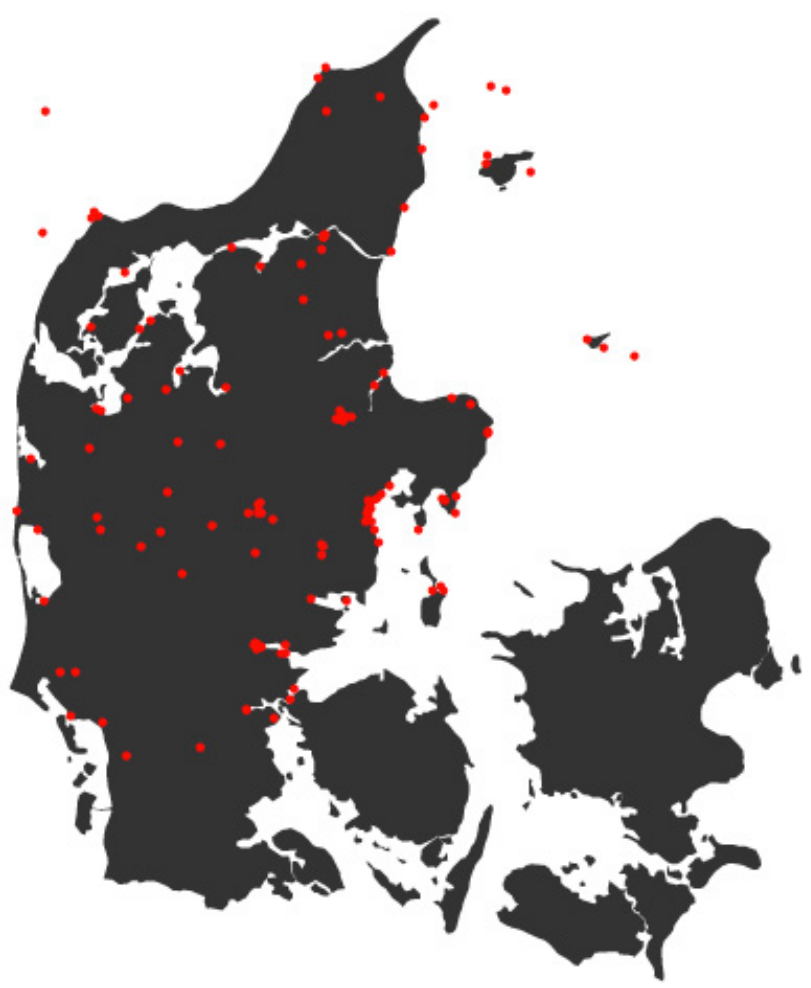

Figure 4. Geographical distribution of cases.

The drownings were geographically relatively evenly distributed with a majority of accidents at the docks in the largest cities Aarhus, Randers and Aalborg (figure 4).

The autopsy findings appear in the tables 4, 5 and 6, showing the average weights of the organs in salt water and fresh water submersions, other autopsy findings and the odds ratio of comparison of findings in salt water and fresh water submersions. Figure 5 illustrates the amount of pleural effusion at different time intervals from death to autopsy. 
Table 4. Mean, Standard deviation, 95\%--prediction interval and 95\%--confidence interval. * $\mathrm{p}$--value is calculated by z-- test of salt water and fresh water submersions Lung weights are gender--divided due to the difference in normal physiological weight..

\begin{tabular}{|c|c|c|c|c|c|c|}
\hline & $\mathbf{N}$ & Mean & SD & 95\% PI & $95 \% \mathrm{Cl}$ & p--value* \\
\hline Spleen weight (g) & 125 & 130.74 & 69.15 & $(--4.79 ; 266.26)$ & $(118.61 ; 142.86)$ & \\
\hline Male & 92 & 142.13 & 72.51 & $(0.010 ; 284.25)$ & $(127.31 ; 156.95)$ & \\
\hline Female & 33 & 98.97 & 46.47 & $(7.89 ; 190.05)$ & $(83.11 ; 114.83)$ & \\
\hline Total lung weight (g) & 127 & 1223.9 & 370.33 & $(498.06 ; 1949.13)$ & $(1158.9 ; 1293)$ & \\
\hline -- Salt water & 72 & 1248.85 & 377.03 & $(509.87 ; 1987.83)$ & $(1161.76 ; 1335.94)$ & \\
\hline -- Fresh water & 55 & 1191.24 & 362.19 & $(481.35 ; 1901.13)$ & $(1095.52 ; 1286.96)$ & $p=0.38$ \\
\hline Male (total) & 92 & 1262.27 & 397.86 & $(482.46 ; 2042.08)$ & $(1180.97 ; 1343.57)$ & \\
\hline Male (salt water) & 58 & 1267.08 & 398.03 & & & \\
\hline Male (fresh water) & 34 & 1254.18 & 403.44 & & & $p=0.88$ \\
\hline Female (total) & 35 & 1123.03 & 264.75 & $(604.12 ; 1641.94)$ & $(1035.32 ; 1210.74)$ & \\
\hline Female (salt water) & 14 & 1173.57 & 272.28 & & & \\
\hline Female (fresh water) & 21 & 1089.33 & 260.75 & & & $p=0.36$ \\
\hline Pleural effusion (ml) & 60 & 643.68 & 505.3 & $(--346.70 ; 1634.06)$ & $(515.82 ; 771.54)$ & \\
\hline -- Salt water & 41 & 707.098 & 489.14 & $(--251.62 ; 1665.81)$ & $(557.37 ; 856.82)$ & \\
\hline -- Fresh water & 19 & 506.84 & 525.63 & $(--523.39 ; 1537.07)$ & $(270.49 ; 743.19)$ & $p=0.16$ \\
\hline
\end{tabular}

Table 5. Autopsy findings associated with drowning cases; absolute numbers (percent). *Missing is due to missing data, missing registration or putrefaction. Other is due to other circumstances, that has complicated the registration.

\begin{tabular}{lcccc}
\hline & Present & Not present & Missing* & Other* \\
\hline Internal froth & $23(17.0 \%)$ & $104(77.0 \%)$ & $7(5.2 \%)$ & $1(0.7 \%)$ \\
External froth & $34(25.2 \%)$ & $93(68.9 \%)$ & $7(5.2 \%)$ & $1(0.7 \%)$ \\
Aqueous gastric content & $61(45.2 \%)$ & $64(47.4 \%)$ & $8(5.9 \%)$ & $2(1.5 \%)$ \\
Emphysema (histological) & $92(68.1 \%)$ & $43(41.9 \%)$ & $0(0.0 \%)$ & $1(0.0 \%)$ \\
Bulging lungs & $33(24.4 \%)$ & $99(73.3 \%)$ & $2(1.5 \%)$ & $0.7 \%)$ \\
Fluids in sinuses & $40(29.6 \%)$ & $38(28.1 \%)$ & $57(42.2 \%)$ & $2(0.0 \%)$ \\
Adipocere & $14(10.4 \%)$ & $119(88.1 \%)$ & $0(0.0 \%)$ & $2(1.5 \%)$ \\
\hline
\end{tabular}

Table 6. Associations water type and autopsy findings, including $95 \%$ confidence interval and p--value. *Adjusted for time in water

\begin{tabular}{lccc}
\hline & OR & 95\% Cl & p--value \\
\hline Adipocere & 1.21 & $(0.49 ; 2.99)$ & 0.68 \\
Adipocere (adj.)* & 1.35 & $(0.50 ; 3.65)$ & 0.55 \\
Bulging lungs & 1.18 & $(0.52 ; 2.70)$ & 0.69 \\
Pleural effusion & 2.37 & $(1.06 ; 2.44)$ & 0.02 \\
Pleural effusion (adj.)* & 2.51 & $(1.18 ; 5.33)$ & 0.02 \\
\hline
\end{tabular}


Figure 6 states the findings of emphysema in different age groups.

Regarding emphysema and water type, no statistical significant association was found (Odds Ratio $(\mathrm{OR})=2.03,95 \% \mathrm{Cl}(0.95 ; 4.34), \mathrm{p}=0.069)$. The same was the case for emphysema and bulging lungs $(\mathrm{OR}=2.02,95 \% \mathrm{Cl}$ $(0.80 ; 5.11), p=0.14)$.

Concerning water type, statistical analysis has been done for association with adipocere $(\mathrm{OR}=1.21,95 \% \mathrm{Cl}(0.49 ; 2.99), \mathrm{p}=0.68)$, bulging lungs $(\mathrm{OR}=1.18,95 \% \mathrm{Cl}(0.52 ; 2.70), \mathrm{p}=0.69)$, lung weight ( $\mathrm{z}$-test, $\mathrm{p}=0.38)$, amount of pleural effusion ( $z$-test, $p=0.16$ ) and prevalence of pleural effusion $(\mathrm{OR}=2.37,95 \% \mathrm{Cl}(1.06 ; 2.44), \mathrm{p}=0.02)$. This has been adjusted for time, since this could affect the prevalence of pleural effusion (figure 5); ( $O R=2.51,95 \%$ $\mathrm{Cl}(1.18 ; 5.33), \mathrm{p}=0.02$ ) (table 6).

\section{DISCUSSION}

Few studies have been done regarding circumstances and autopsy findings in drownings in Denmark. In Kringsholm et al. [9] 45 (61\%) of cases had a positive alcohol analysis, which is similar to the findings in this study. This indicates, that alcohol is an essential factor in drowning deaths. They furthermore described, that the most frequent site of incident was the ocean, in canals and in docks, which also is corresponding to the findings in this study. It could be interesting to examine the mean alcohol intake in the concerning regions of Denmark per year and compare it to the number of drowning deaths to investigate a possible connection between the societal alcohol consumption and number of drownings. This could also be addressed by comparing number of drowning deaths in different countries with the alcohol consumption in these countries.

The lung weights in this study were elevated proportional to normal lung weights, which was expected from Hadley et al. and Yorulmaz et al. $[10,12]$. Comparing lung weights in submersions and in other causes of death, they discovered, that the lungs in submersions were heavier. Comparing with a reference group, Kringsholm et al. found, that the lungs of drowning victims were significantly heavier than that of the references, but as was the case in our study, there was no difference in lung weights in salt water and fresh water submersions.

We found no difference in the amount of pleural effusion in salt water and fresh water submersions. By contrast, it cannot be excluded that pleural effusion is more often present in salt water submersions than in fresh water submersions. As pleural effusion has been correlated to the time a body has been submerged post mortem [13], the association in our study was time-stratified, which simply caused the odds ratio to increase with the same $p$-value, indicating association between pleural effusion and salt water submersions. Yorulmaz et al. [12] likewise found larger amounts of pleural effusion in salt water submersions, but no significant association of pleural effusion in fresh water submersions. In addition to time as part of the putrefaction process, pleural effusion has also been correlated to other causes of deaths than drowning, such as acute cardiac death and asphyxiation $[16,17]$.

Yorulmaz et al. [12] investigated increase in pleural fluid as a sign of drowning by comparing a group of drowning cases with a group of non-drowning cases. The non-drowning cases died from strangulation, stabbing and intoxication. The mean amount of pleural effusion in the drowning cases was $705 \mathrm{ml}$ compared to $90 \mathrm{ml}$ in the non-drowning cases. Kringsholm et al. found various amounts of pleural effusion in the drowning

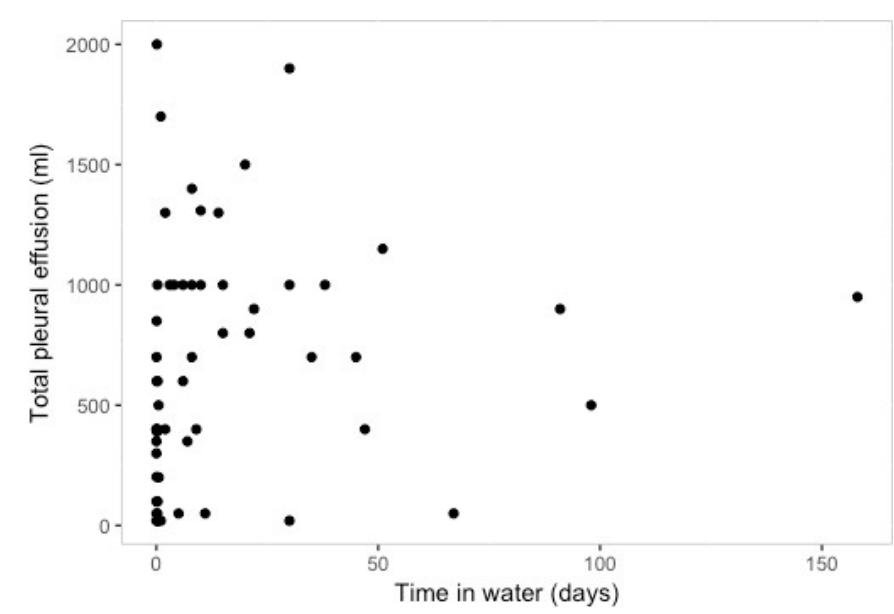

Figure 5. Pleural effusion grouped in time, the body spent in water.

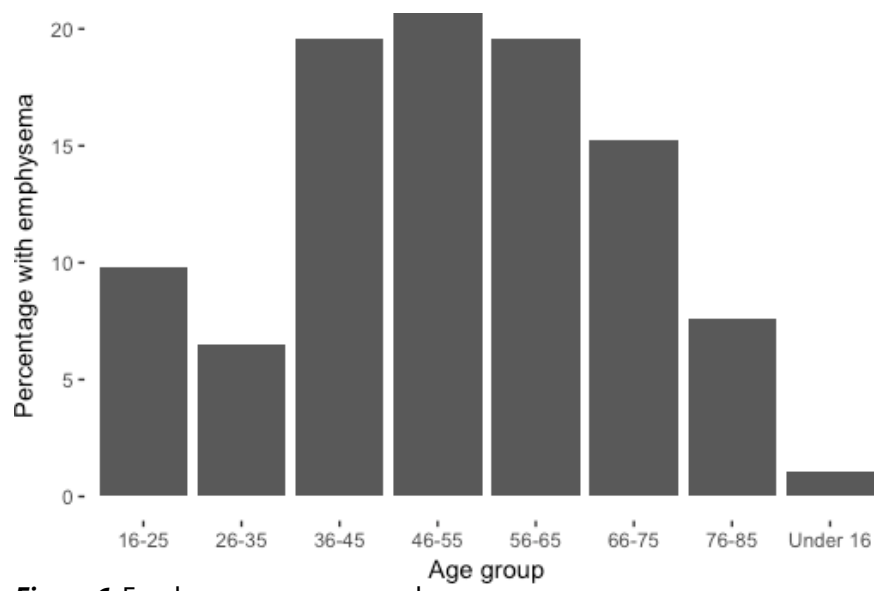

Figure 6. Emphysema, age grouped.

cases investigated, but no incidence of pleural effusion within controls, that where dead by gunshots. An interesting development of this study could be to compare the amount of pleural effusion in the drowning cases with the amount in cases with other causes of death.

The autopsy findings are relatively inconsistent. Emphysema was seen in $92(68.1 \%)$ of cases. This is a relatively frequent occurrence, which could be interesting regarding autopsy findings in drowning. It is however difficult to determine whether the emphysema was present before the drowning or caused by the drowning (emphysema aquosum). Klysner et al. [18] and Kohlhase et al. [19] have discussed this. Fluid in paranasal sinuses was quite often not noted in the data, possibly because of missing examination, missing registration or no CT-scan.

Part of the data was missing due to putrefaction and/or destruction of the tissue owing to the time spent in water. In addition to that, the autopsy findings can depend on the individual examiner. Concerning the weight of the organs, a gender-distribution has been done in the analysis of lung and spleen weights, to take account for the majority of men in this study.

This study only includes drowning deaths where an autopsy has been performed, and is thus based on a selected material. All drowning deaths from Denmark are registered and divided into manner of death in the Danish Cause of Death Register [20]. In 2006-2015, the drowning deaths were $345(45.5 \%)$ accidents, 350 (46.1\%) suicides and approximately 65 
(8.6\%) by undetermined manner of death, were registered. This indicates, that the present material has been selected in favour of accidents. The gender distribution however, was the same as in the present study $(70 \%$ and $30 \%$ ). A further development of this study could be to compare these cases of drowning deaths to corresponding cases with another cause of death - this could be deceased with strangulation related causes of death or deceased with lung diseases as causes of death. The reference groups should then be selected to match the cases in variables such as e.g. gender, age, time from death to autopsy etc. It could also be interesting to investigate the possibilities of CT-scan in drowning cases, e.g. comparison of autopsy findings with $\mathrm{CT}$ findings concerning drowning deaths.

\section{CONCLUSION}

The majority of drowning victims examined at the Department of Forensic Medicine University of Aarhus 2006-2015 were males, of which many had a positive alcohol analysis. This study found no significant association between water type of submersion and amount of pleural effusion, lung weight, spleen weight, adipocere or bulging lungs. However, a significant association between the presence of pleural effusion and water type cannot be discounted. The average lung weight was relatively high compared to standard weights.

\section{REFERENCES}

[1] B. Laursen, K. Juel, Druknedødsfald i Danmark 2001-2014. Statens Institut for Folkesundhed, 2016

[2] Sundhedsstyrelsen, Dødsårsagsregisteret (DAR), eSundhed.dk, 2017. Information om dødsårsager fra 1970-2015.

[3] Indbyggertal, Danmarks statistik, 4. kvartal 2016, http://www.statistikbanken. $\mathrm{dk} / 10021$

[4] Areal, Danmarks statistik, https://www.statbank.dk/statbank5a/SelectVarVal/ define.asp? MainTable=ARE207\&PLanguage $=0 \& T \quad$ abstrip $=\& P X S I d=0 \& S e s s I D=$ 202220032\&FF $=20 \&$ grouping $1=2013114144511116568165 \&$ tfrequency $=1$, 2017.

[5] Areal, Danmarks statistik, http://www.dst.dk/da/Statistik/Publikationer/ VisPub?cid=20702, udgivet 1968, besøgt 2017.

[6] K. Juel, Dødeligheden i Danmark gennem 100 år. Statens Institut for Folkesundhed, (2004).

[7] Sundhedsstyrelsen \& Statens Serum Institut, Alkoholstatistik 2015 Nationale data, (2015).

[8] H. Th. Haffner, M. Graw, J. Erdelkamp, Spleen findings in drowning, Forensic Sci. Int., 66, pp. 95-104, (1994).

[9] B. Kringsholm, A. Filskov, K. Kock, Autopsied cases of drowning in Denmark 19871989, Forensic Sci. Int., 52, 1, pp. 85-92, (1991).

[10] J. A. Hadley, D. R. Fowler, Organ weight effects of drowning and asphyxiation on the lungs, liver, brain, heart, kidneys and spleen, Forensic Sci. Int., 133, 3, pp. 190 196, (2003).
[11] B. Knight, P. Saukko, Knights Forensic Pathology, third edition, 2004, Arnold, (p. 395-408, 606).

[12] C. Yorulmaz, N. Arican, I. Afacan, H. Dokgoz, M. Asirdizer, Pleural effusion in bodies recovered from water, Forensic Sci. Int., 136, 1-3, pp. 16-21, (2003).

[13] H. Hyodoh, J. Shimizu, S. Watanabe, S. Okazaki, K. Mizuo, H. Inoue, Time-related course of pleural space fluid collection and pulmonary aeration on postmortem computed tomography (PMCT), Legal Medicine, 17, pp. 221-225, (2015).

[14] Om alkohol, Kræftens Bekæmpelse og Trygfonden, http://www.omalkohol.dk/ krop-sundhed/alkohol- promille-og-procenter/, 2018.

[15] Sundhed.dk, https://www.sundhed.dk/borger/patienthaandbogen/psyke/ sygdomme/alkohol/alkohol- fakta/, 2018.

[16] Wardak, Khalil S (03.2014). "The Drowning Index: implementation in drowning, mechanical asphyxia, and acute myocardial infarct cases... Journal of forensic sciences (0022-1198), 59 (2), p. 399.

[17] Zhu, Bao-Li (03.2003). „Postmortem lung weight in drownings: a comparison with acute asphyxiation and cardiac death... Legal medicine (Tokyo, Japan) (13446223), 5 (1), p. 20.

[18] A. Klysner, N. Lynnerup, H. P. Hougen, Is acute alveolar dilation an indicator of strangulation homicide?, Med Sci. Law, 51, 2, pp. 102-105, (2011).

[19] C. Kohlhase, H. Maxeiner, Morphometric investigation of emphysema aquosum in the elderly, Forensic Sci. Int., 134, 2-3, pp. 93-98, (2003).

[20] Dødsårsagsregisteret, DAR, https://sundhedsdatastyrelsen.dk/dar, (5/10-2017). 